\title{
Solitary fibrous tumor located in the sella turcica: A report of two cases and review of the literature
}

\author{
XIAO YANG, QINGJUN JIANG and BINGBING YU \\ Department of Medical Imaging, Jinan Military General Hospital, Jinan, Shandong 250031, P.R. China
}

Received May 31, 2014; Accepted February 13, 2015

DOI: $10.3892 / \mathrm{ol} .2015 .3162$

\begin{abstract}
Solitary fibrous tumors (SFTs) of the sella turcica are rare entities, with only four cases reported in the literature thus far. The current study describes two cases of SFT arising from the sella turcica, including presentation of the clinical, imaging and histopathological findings, and the initial treatment strategies and diagnosis, with emphasis on the treatment of the tumor in this unusual location. Magnetic resonance imaging is a useful method for identifying a solid or heterogeneous mass; however, histopathological and immunohistochemical data are required to clarify such diagnoses. The majority of SFTs exhibit clinically benign behavior and have a positive outcome; however, certain SFTs may present malignant features. Although gross total resection of SFTs in the sella turcica is important, subtotal resection with subsequent stereotactic radiotherapy is proposed as an acceptable alternative. Furthermore, careful and long-term follow-up of patients with SFT of the sella turcica is required as the clinical outcome is unpredictable.
\end{abstract}

\section{Introduction}

A solitary fibrous tumor (SFT) is a type of spindle cell tumor that was initially described as a tumor of the pleura and peritoneum; however, it has also been identified in the central nervous system, head and neck, visceral organs, skin and soft tissues. For instance, SFTs have been described in the meninges, paranasal sinuses, oral cavity, throat, orbit, lungs, liver, thyroid, kidney, bladder and genitals (1-8). SFTs are uncommon in thoracic and extrathoracic locations, with thoracic SFTs accounting for $<5 \%$ of all pleural neoplasms (9). SFTs principally affect middle-aged adults (mean age, 51 years; range, 5-87 years) and exhibit no gender predilection $(3,8)$. The majority of thoracic

Correspondence to: Dr Qingjun Jiang, Department of Medical Imaging, Jinan Military General Hospital, 25 Shifan Road, Jinan, Shandong 250031, P.R. China

E-mail: qingjunjiang@163.com

Key words: solitary fibrous tumor, sella turcica, cluster of differentiation 34, magnetic resonance imaging, stereotactic radiotherapy
SFTs are asymptomatic while extrathoracic SFTs are usually symptomatic, depending on tumor location and the size of the mass. Symptoms of SFT in the head and neck are nonspecific; headaches often occur in intracranial lesions and visual disturbances, poor memory, finger clubbing and hypoglycemia have also been reported $(2,6)$. The majority of SFTs exhibit benign behavior and have a good outcome; however, certain cases may have malignant features. In 10-15\% of cases, SFT recurrence and/or metastasis may occur; thus, it is difficult to predict the postsurgical course of the disease $(10,11)$.

SFTs rarely occur in the sella turcica, with only four cases of sellar SFT described in the literature thus far (6,12-14) (Table I). SFTs can be easily misdiagnosed as they rarely occur and share similar radiological and clinical symptoms with other sella turcica tumors, including macroadenoma, meningioma and craniopharyngioma $(6,12,14)$. The present study reports two cases of SFT arising from the sellar region with suprasellar extension. The clinical, imaging and histopathological findings, as well the surgical outcomes, were discussed and recommendations for the treatment of SFTs in the sella turcica were proposed. Written informed consent was obtained from both patients.

\section{Case report}

Case one. In March 2011, a 20-year-old female presented with a one-year history of menstrual disorder and five months of deteriorating vision and was admitted to the Jinan Military General Hospital (Jinan, China). Physical examination revealed left-temporal hemianopsia and decreased visual acuity of the right eye, while the prolactin levels were marginally elevated $(591.7 \mu \mathrm{lU} / \mathrm{ml}$; normal range, 102-496 $\mu \mathrm{lU} / \mathrm{ml}$ ). Magnetic resonance imaging (MRI) identified a well-marginated mass centered within the sellar and suprasellar region. The mass extended into the sphenoid sinus, compressed and elevated the optic chiasm, invaded the left cavernous sinus and encased the cavernous internal carotid artery. Furthermore, the lesion demonstrated low and high signal intensities on T2-weighted images (T2-WIs) and an isointense signal on T1-WIs (Fig. 1A and B), as well as acute heterogeneous enhancement on post-contrast T1-WIs (Fig. 1C and D). Dural enhancement was identified in the anterior cranial fossa (Fig. 1D). The initial diagnosis was a pituitary macroadenoma; therefore, endoscopic transnasal transsphenoidal microsurgery was performed. The 
Table I. Reported cases of sella turcica solitary fibrous tumor as described in the literature, including the present two cases.

\begin{tabular}{|c|c|c|c|c|c|c|c|c|}
\hline Patient & $\begin{array}{l}\text { Author } \\
\text { (year) }\end{array}$ & Gender & $\begin{array}{l}\text { Age, } \\
\text { years }\end{array}$ & Symptoms & $\begin{array}{l}\text { Neuroimaging } \\
\text { examination } \\
\text { results }\end{array}$ & $\begin{array}{l}\text { Extent of } \\
\text { invasion }\end{array}$ & Surgery & $\begin{array}{l}\text { Status } \\
\text { at last } \\
\text { follow-up }\end{array}$ \\
\hline 1 & $\begin{array}{l}\text { Cassarino } \\
(2003)\end{array}$ & $\mathrm{F}$ & 54 & $\begin{array}{l}\text { Headaches and visual } \\
\text { impairment }\end{array}$ & $\begin{array}{l}\text { Solid enhancing } \\
\text { intrasellar mass }\end{array}$ & $\begin{array}{l}\text { Encased the carotid } \\
\text { artery and involved } \\
\text { the sphenoid and } \\
\text { cavernous sinuses }\end{array}$ & STR & NA \\
\hline 2 & $\begin{array}{l}\text { Pakasa } \\
(2005)\end{array}$ & $\mathrm{F}$ & 66 & $\begin{array}{l}\text { Headaches and visual } \\
\text { impairment }\end{array}$ & $\begin{array}{l}\text { Solid enhancing } \\
\text { intrasellar mass }\end{array}$ & $\begin{array}{l}\text { Extension to } \\
\text { the optic chiasm } \\
\text { cavernous sinus and } \\
\text { carotid arteries }\end{array}$ & STR & $\begin{array}{l}14,26 \text { and } \\
62 \text { months } \\
\text { Rec, } \\
78 \text { months } \\
\text { deceased }\end{array}$ \\
\hline 3 & $\begin{array}{l}\text { Furlanetto } \\
\text { (2009) }\end{array}$ & M & 28 & Visual impairment & $\begin{array}{l}\text { Solid enhancing } \\
\text { intrasellar mass }\end{array}$ & $\begin{array}{l}\text { Compressed the } \\
\text { optic chiasm }\end{array}$ & GTR & $\begin{array}{l}10 \text { months } \\
\text { NED }\end{array}$ \\
\hline 4 & $\begin{array}{l}\text { Yin } \\
(2010)\end{array}$ & M & 32 & $\begin{array}{l}\text { Headache, } \\
\text { ophthalmalgia } \\
\text { and visual impairment }\end{array}$ & $\begin{array}{l}\text { Solid enhancing } \\
\text { intrasellar mass }\end{array}$ & $\begin{array}{l}\text { Compressed the } \\
\text { left optical nerve } \\
\text { and chiasma }\end{array}$ & STR & $\begin{array}{l}44 \text { months } \\
\text { NED }\end{array}$ \\
\hline 5 & $\begin{array}{l}\text { Present } \\
\text { case }\end{array}$ & F & 20 & $\begin{array}{l}\text { Headaches and visual } \\
\text { impairment }\end{array}$ & $\begin{array}{l}\text { Solid enhancing } \\
\text { intrasellar mass }\end{array}$ & $\begin{array}{l}\text { Compressed the } \\
\text { optic chiasm, } \\
\text { invaded the left } \\
\text { cavernous sinus } \\
\text { and encased the } \\
\text { carotid artery }\end{array}$ & STR & $\begin{array}{l}4 \text { years } \\
\text { NED }\end{array}$ \\
\hline 6 & $\begin{array}{l}\text { Present } \\
\text { case }\end{array}$ & M & 22 & Visual impairment & $\begin{array}{l}\text { Solid enhancing } \\
\text { intrasellar mass }\end{array}$ & $\begin{array}{l}\text { Compressed the } \\
\text { optic chiasm, and } \\
\text { encased the anterior } \\
\text { cerebral artery }\end{array}$ & GTR & $\begin{array}{l}2 \text { years } \\
\text { NED }\end{array}$ \\
\hline
\end{tabular}

M, male; F, female; STR, subtotal removal; GTR, gross total removal; NED, no evidence of disease; Rec, recurrence; NA, not available.

A

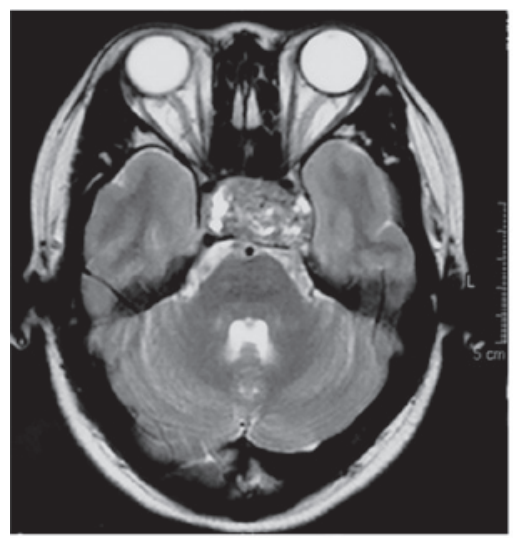

C

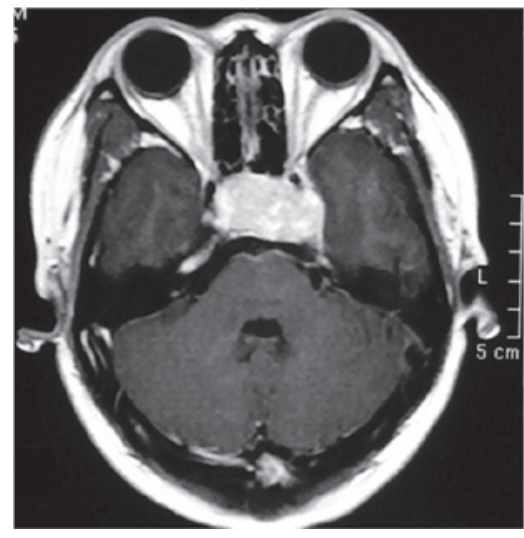

B

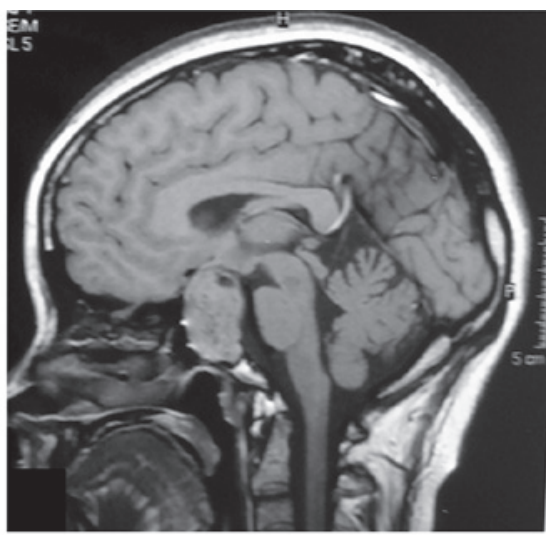

D

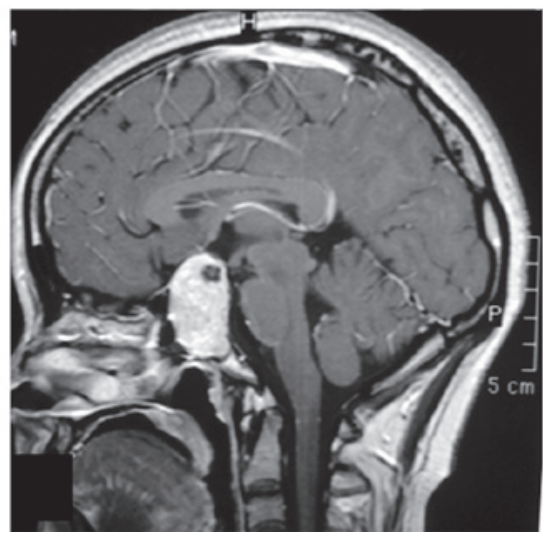

Figure 1. Magnetic resonance imaging findings for case one. In the (A) axial and (B) sagittal view, a mass was detected inside the pituitary fossa; however, a normal pituitary gland was not identified. (C) Axial and (D) sagittal T1-weighted images exhibited strong heterogeneous contrast enhancement. 

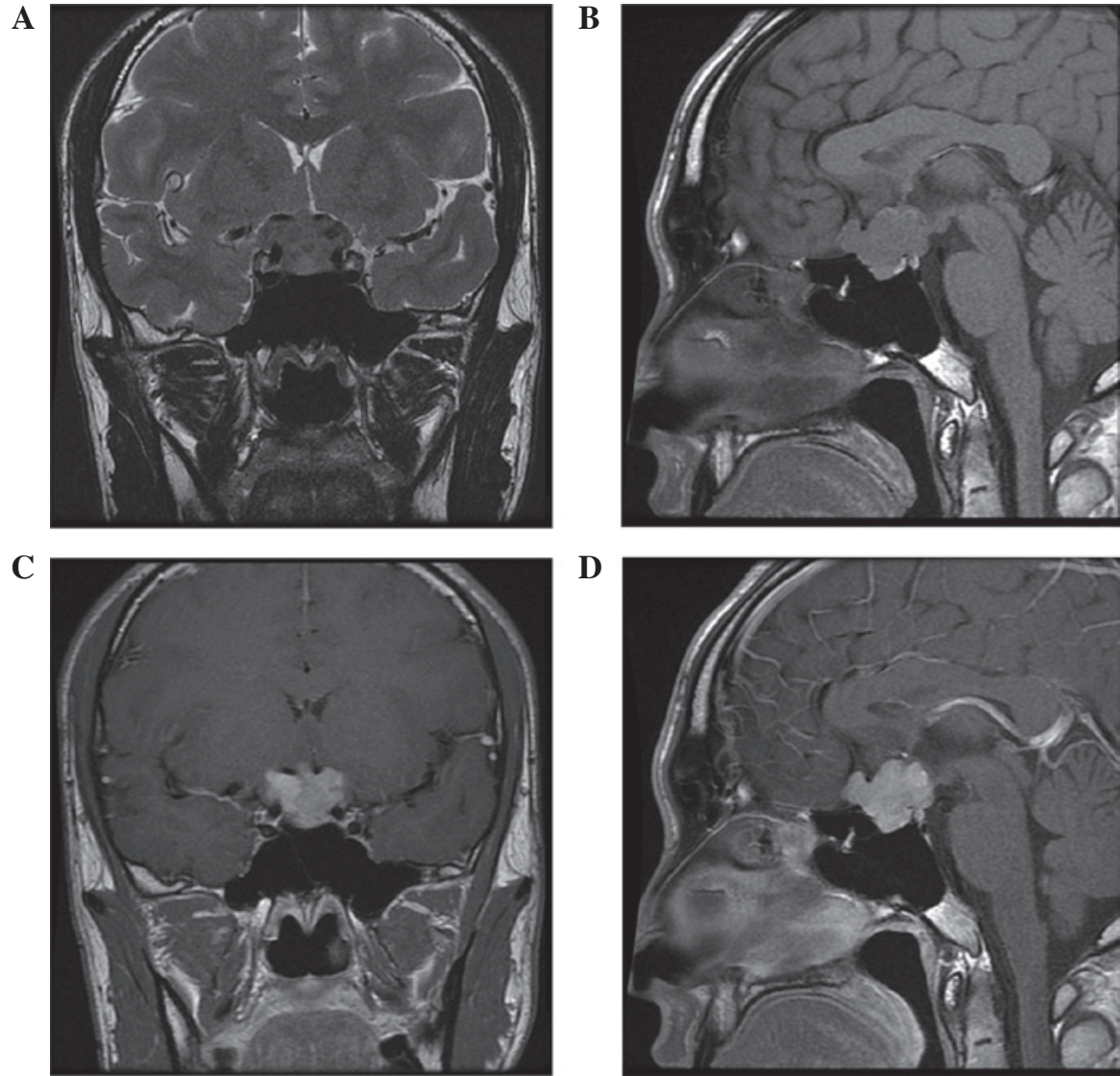

Figure 2. Magnetic resonance imaging findings for case two. A mass was identified inside the pituitary fossa on the (A) coronal T2-weighted image (WI) and (B) sagittal T1-WI, and a normal pituitary gland was identified. (C) Coronal and (D) sagittal T1-WI sequences exhibited strong heterogeneous contrast enhancement.

microsurgery identified a firm, highly vascular, brick red-colored tumor in the sellar that bled easily during surgery. The surgery was prematurely terminated due of excessive bleeding; therefore, only a small section of the tumor was resected. Microscopic examination revealed that the tumor was composed of highly atypical spindle cells with varying degrees of fibrosis and interspersed with a branching vascular component. Areas of cellular pleomorphism and increased cellularity were present; however, mitosis was not identified (Fig. 3A). Furthermore, Ki-67 expression exhibited scattered positivity ( $2 \%$ of tumor cells), indicating a low level of active proliferation (Fig. 3B). Immunohistochemical staining identified that the tumor cells were diffusely positive for vimentin (Fig. 3C), cluster of differentiation (CD) 34 (Fig. 3D) and CD99. By contrast, the tumor cells were negative for epithelial membrane antigen (EMA) and S-100 protein. These findings confirmed the diagnosis of SFT. In April 2011, the patient underwent a second craniotomy at Peking Union Medical College Hospital (Beijing, China). Again, complete resection was not achieved due to excessive hemorrhage. The patient is currently undergoing follow-up MRI examination every 6 months and at the time of writing was well with no evidence of residual tumor progression.

Case two. In February 2013, a 22-year-old male presented with a five-month history of progressive reduced visual acuity and visual field impairment and was admitted to the Jinan Military General Hospital (Jinan, China). Laboratory examinations, including endocrine investigations, revealed no abnormalities. General examination of the patient was also normal. However, an MRI scan identified a $1.7 \times 2.4-\mathrm{cm}^{2}$ irregular, well-marginated mass located in the sella and suprasellar region. The mass compressed and elevated the optic chiasm and encased the anterior cerebral artery. However, the cavernous sinus was not invaded. Furthermore, healthy pituitary tissue was detected, although the edge was unclear. On T1-WIs, the lesion exhibited isointense signals relative to grey matter. Additionally, the mass was inhomogeneous on T2-WIs and demonstrated homogeneous enhancement following intravenous administration of $15 \mathrm{ml}$ gadolinium (Fig. 2A-D). Based on the aforementioned findings, the initial diagnosis was nonfunctional pituitary macroadenoma; therefore, a craniotomy was performed. Intraoperatively, a firm, fibrous and well-circumscribed mass was observed in the sellar region, with cerebral dural matter infiltrating, but not invading, the pituitary gland. The tumor was completely removed; however, blindness in the left eye occurred following surgery, possibly due to damage to the blood vessel of the optic chiasm. Microscopically, the tumor was composed of clusters of spindle-shaped cells interspersed between dense collagen bundles and vascular channels, without atypia (Figure. 3E). Ki-67 expression exhibited scattered positivity (2-5\% of tumor cells), indicating a low level of active proliferation. Immunohistochemical staining identified that the tumor cells were positive for CD34 (Fig. 3F) and vimentin (Fig. 3G) but negative for EMA (Fig. 3H) and S-100 protein. Histological and immunohistochemical analysis of 

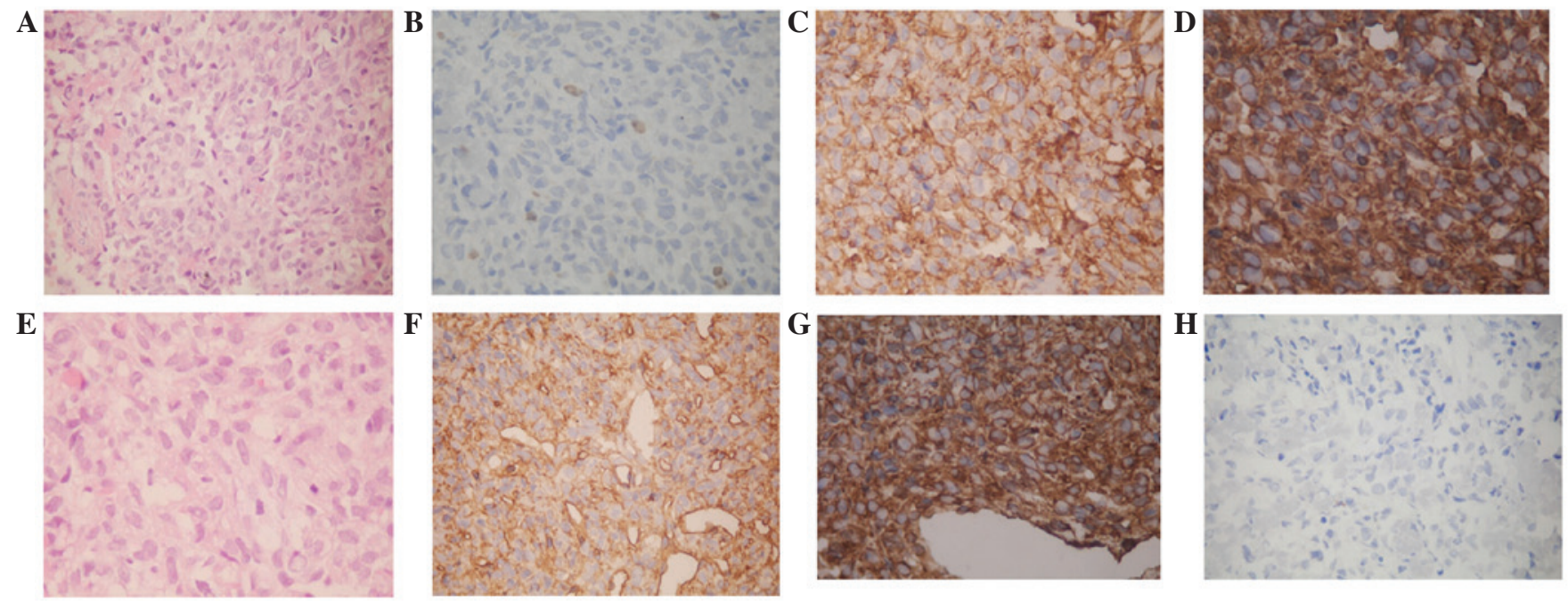

Figure 3. Immunohistochemical staining in the resected tumors of case one and two. Case one. (A) The tumor consisted of highly spindle cells in a dense hyalinized collagenous stroma, which consisted of alternating hypercellular and hypocellular areas, while thin-walled staghorn branching vessels were identified (hematoxylin and eosin staining; magnification, x200). (B) Ki-67 demonstrated scattered positivity (2\% of tumor cells) (magnification, x200). Immunohistochemically, the tumor cells exhibited strong positive staining for $(C)$ vimentin (magnification, $x 400)$ and (D) CD34 (magnification, $x 400)$. Case two. (E) The tumor was composed of spindle cells interspersed between dense collagen bundles and vascular channels, without atypia (hematoxylin and eosin staining; magnification, x200). Immunohistochemically, the tumor cells exhibited positive staining for (F) CD34 (magnification, x400) and (G) vimentin (magnification, $\mathrm{x} 400$ ) and negative staining for $(\mathrm{H})$ epithelial membrane antigen (magnification, $\mathrm{x} 200$ ). CD, cluster of differentiation.

the resected tumor identified determined results similar to case one, thus, resulting in a diagnosis of SFT. Follow-up MRI examinations every 6 months were planned and at the time of writing the patient was asymptomatic with no evidence of disease or recurrence.

\section{Discussion}

Numerous SFT cases have been identified in the central nervous system (CNS). However, a literature search of the PubMed database (http://www.ncbi.nlm.nih.gov/pubmed), using the search term 'sella turcica solitary fibrous tumor' revealed that only four cases involving the sella turcica have been published in the English literature to date $(6,12-14)$ (Table I); thus, the sella turcica is a relatively uncommon site of SFT. In light of its rarity and considering that SFT may mimic other types of tumor located in the sellar and suprasellar area, SFT of the sella turcica is easily misdiagnosed prior to surgery. The six known SFT cases, including the four cases reported in the literature $(6,12-14)$ and the two cases reported in the present study, were initially diagnosed as pituitary macroadenomas. Among the six cases, three were male and three were female patients, with an age range of 20-66 years and an average age of 37 years.

Clinically, SFTs are slow-growing and their symptoms depend on the tumor size (maximum length along the sagittal plane, 2-3 cm) (14). The four previously-described cases presented with reduced visual acuity and visual field impairment. Endocrine investigations were normal, with the exception of case one in the present study, in which prolactin levels were mildly elevated; this is described as the stalk section effect, where the pituitary stalk may become compressed due to suprasellar tumors, resulting in subsequent hyperprolactinemia (15). However, these clinical features are non-specific.
Radiological investigation identified a heterogeneous mass inside and above the pituitary fossa in six cases (images not provided in two cases). The pituitary gland was located in case two of the present study; however, it was not clearly identifiable in all other cases. Comparing the six known cases of sellar SFT, including the two cases of the present study, the following were determined as common features of sellar SFTs: Well-marginated mass, inhomogeneous on T2-WI, homogeneous and isointense signal on T1-WI, acute enhancement on post-contrast T1-WI and local invasion. In addition, cavernous sinuses were invaded in $3 / 6$ cases, the carotid artery was encased in $3 / 6$ cases, and the sphenoid and temporal bones were infiltrated in 1/6 cases. No pathognomonic findings were elucidated and sellar SFTs were demonstrated to share similar imaging characteristics with pituitary macroadenomas $(6,12,13,16)$. Therefore, although the occurrence of SFT in the sellar turcica is rare, it should be considered during differential diagnosis.

The pathological features of an SFT of the sella turcica resemble those described for SFTs in other regions. For instance, immunohistochemically, the six sellar SFT cases exhibited reactivity with CD34 and vimentin, but were negative for S-100 protein, smooth muscle actin and EMA. Five cases were positive for CD99, while one case was negative. Although CD34 may be negative in a small number of cases (range, 5-30\%), strongly positive CD34 staining is a characteristic immunohistochemical feature of SFTs (17).

The six reported cases of SFT underwent surgery. Endoscopic transnasal transsphenoidal microsurgery was performed in three cases $(12,13)$, with the tumor being completely resected in one case (12), which resulted in a cerebrospinal fluid (CSF) fistula. The tumor was incompletely removed in the other two cases $(13,14)$. In the other three cases, craniotomy with a fronto-pterional approach was performed (6), with complete tumor resection in one case, which resulted in blindness. The 
tumor was incompletely removed in the other two cases (6). Generally, the tumors were hard, locally invasive and highly vascularized, precluding complete resection. Stereoradiotherapy was performed in two cases $(13,14)$; one patient succumbed due to uncontrolled disease progression (13) and the other patient was followed up for 44 months with no indication of progression or distant metastasis of the residual tumor (14).

In conclusion, it has been previously reported that stereotactic and external beam radiotherapy are effective treatment strategies for residual or inoperable recurrences of SFT (14,17-19). Therefore, since complete resection may result in complications such as CFS fistulas and blindness, while stereotactic radiotherapy is known to be effective, the present study proposes that a subtotal resection should be considered as an acceptable surgical approach for the treatment of recurrent or residual intracranial SFTs in cases where removal of the sellar tumor is difficult. In addition, careful follow-up is required in all cases of sellar SFT as the tumor exhibits long-term malignant potential and an unpredictable clinical outcome. However, drawing definite conclusions is difficult due to the limited number of cases reported in the literature to date.

\section{References}

1. Caroli E, Salvati M, Orlando ER, Lenzi J, Santoro A and Giangaspero F: Solitary fibrous tumors of the meninges: report of four cases and literature review. Neurosurg Rev 27: 246-251, 2004.

2. Metellus P, Bouvier C, Guyotat J, Fuentes S, Jouvet A, Vasiljevic A, Giorgi R, Dufour H, Grisoli F and Figarella-Branger D: Solitary fibrous tumors of the central nervous system: clinicopathological and therapeutic considerations of 18 cases. Neurosurgery 60: 715-722, 2007.

3. Nai GA and Ramalho Neto GC: Solitary fibrous tumor of the nasal cavity. Braz J Otorhinolaryngol 75: 769, 2009.

4. Sun K, Lu JJ, Teng XD, Ying LX and Wei JF: Solitary fibrous tumor of the liver: a case report. World J Surg Oncol 9: 37, 2011.

5. Wignall OJ, Moskovic EC, Thway K and Thomas JM: Solitary fibrous tumors of the soft tissues: review of the imaging and clinical features with histopathologic correlation. AJR Am J Roentgenol 195: W55-W62, 2010.

6. Cassarino DS, Auerbach A and Rushing EJ: Widely invasive solitary fibrous tumor of the sphenoid sinus, cavernous sinus, and pituitary fossa. Ann Diagn Pathol 7: 169-173, 2003.
7. Kim SA, Hwang JE, Ro JY, Cho KJ, Song C and Kim MJ: Solitary fibrous tumor of the kidney: A report of two cases with review of literature. Korean J Pathol 44: 420-425, 2010.

8. Talvitie H, Aström K, Larsson O, Ahlén J, Bergh A and Egevad L: Solitary fibrous tumor of the prostate: a report of two cases. Pathol Int 61: 536-538, 2011.

9. Cardillo G, Carbone L, Carleo F, Masala N, Graziano P, Bray A and Martelli M: Solitary fibrous tumors of the pleura: An analysis of 110 patients treated in a single institution. Ann Thorac Surg 88: 1632-1637, 2009.

10. Ning S, Song X, Xiang L, Chen Y, Cheng Y and Chen $\mathrm{H}$ : Malignant solitary fibrous tumor of the thyroid gland: report of a case and review of the literature. Diagn Cytopathol 39: 694-699, 2011.

11. Ikeda T, Wada N, Nomura M, Tamiya S and Ushijima M: A case of solitary fibrous malignant tumor with multiple metastases. Nihon Kokyuki Gakkai Zasshi 49: 913-916, 2011 (In Japanese).

12. Furlanetto TW, Pinheiro CF, Oppitz PP, de Alencastro LC and Asa SL: Solitary fibrous tumor of the sella mimicking pituitary adenoma: an uncommon tumor in a rare location - a case report. Endocr Pathol 20: 56-61, 2009.

13. Pakasa NM, Pasquier B, Chambonnière ML, Morrison AL, Khaddage A, Perret AG, Dumollard JM, Barral FG and Péoc'h M: Atypical presentations of solitary fibrous tumors of the central nervous system: an analysis of unusual clinicopathological and outcome patterns in three new cases with a review of the literature. Virchows Arch 447: 81-86, 2005.

14. Yin W, Ma C, Wu J, Cai B and You C: A primary atypical solitary fibrous tumor of the sella mimicking nonfunctional pituitary adenoma: a case report. Acta Neurochir (Wien) 152: 519-522, 2010.

15. Rupp D and Molitch M: Pituitary stalk lesions. Curr Opin Endocrinol Diabetes Obes 15: 339-345, 2008.

16. Vassal F, Manet R, Forest F, Camdessanche JP, Péoc'h M and Nuti C: Solitary fibrous tumors of the central nervous system: report of five cases with unusual clinicopathological and outcome patterns. Acta Neurochir (Wien) 153: 377-384, 2011.

17. Bisceglia M, Galliani C, Giannatempo G, Lauriola W, Bianco M, D'Angelo V, Pizzolitto S, Vita G, Pasquinelli G, Magro G and Dor DB: Solitary fibrous tumor of the central nervous system: a 15-year literature survey of 220 cases (August 1996-July 2011). Adv Anat Pathol 18: 356-392, 2011.

18. Saynak M, Bayir-Angin G, Kocak Z, Oz-Puyan F, Hayar M, Cosar-Alas R, Karamustafaoglu A, Yurut-Caloglu V, Caloglu M and Yoruk Y: Recurrent solitary fibrous tumor of the pleura: significant response to radiotherapy. Med Oncol 27: 45-48, 2010.

19. Reames DL, Mohila CA and Sheehan JP: Treatment of intracranial solitary fibrous tumors with gamma knife radiosurgery: report of two cases and review of literature. Neurosurgery 69: E1023-E1028, 2011. 